\title{
Denied Investment: A Case of Community Member's Attitudes towards Volunteering in Corporate Social Investment Initiatives
}

\author{
${ }^{1}$ Paul-Francois Muzindutsi, ${ }^{2}$ Ferdinand Niyimbanira \\ ${ }^{1}$ North-West University, Vaal Triangle Campus, South Africa \\ ${ }^{2}$ Vaal University of Technology, Vanderbijlpark Campus, South Africa \\ 24754293@nwu.ac.za
}

\begin{abstract}
Companies use corporate social responsible investment (CSI) initiatives to contribute to the wellbeing of the society they operate in. South African companies continue to increase their involvement in CSI initiatives in the areas of education and training, capacity building, community development and health care. The impact of these initiatives can be extended, if community members, who are mostly the beneficiaries of these initiatives, are willing to work with companies through volunteering in CSI initiatives. This study used a combination of qualitative and quantitative research designs to assess the attitude of community towards volunteering on a CSI project. Interviews and survey questionnaire were used to collect data from households' members who benefited from a CSI initiative of re-roofing houses in one of low income areas of South Africa. Qualitative analysis revealed that the CSI project provided skill which opened employment opportunities to community members who worked on the project. However, quantitative results showed that only $30 \%$ of participants were willing to volunteer on the CSI project. The majority of those who were not willing to volunteer on the CSI project were unemployed and did not have any skills; implying that volunteering on the CSI project could have provided them with some skills. Based on the investment model of volunteering, findings of this study showed that beneficiaries of the CSI initiative denied an investment opportunity due to their attitude towards volunteering. Hence, it was concluded that CSI initiatives could have a greater impact if community members are encouraged to participate in CSI initiatives as volunteers.
\end{abstract}

Keywords: Corporate social investment, volunteering, community members, South Africa

\section{Introduction}

A volunteer is someone who maybe has the aim to benefit or help a stranger, friends, relatives, him/herself, or some combination of these beneficiaries (Brown (1999). However, Wilson and Musick (1997:141) tend to differ slightly by defining a volunteer as someone, "who contributes time to helping others with no expectation of pay or other material benefit to herself." In other words, volunteer activity is the work performed without monetary recompense (Freeman, 1997). Similarly, Ellis and Noyes (1990:4) define volunteering narrowly by stating that, "to volunteer is to choose to act in recognition of a need, with an attitude of social responsibility without concern for monetary profit, going beyond one's basic obligations". Likewise, volunteering means any activity in which time is given freely to benefit another person, group or cause (Wilson, 2000:216). Generally, it is considered as an altruistic activity, intended to promote good or improve the quality of life. Volunteerism may have different meanings to different people. Ascoli \& Cnaan (1997) define volunteerism as, a social phenomenal of unpaid care and citizen participation in society and is highly regarded in all parts of the world." According to Penner (2004: 645), "volunteerism is one form of civic participation which includes long-term, planned, and nonobligatory prosocial activities that benefit another person, cause or group." Wilson (2000) confirms that typically, volunteerism is proactive rather than reactive, and entails some commitments of time and effort.

Volunteerism is not associated with non-profit organisations only, but also with public and for-profit organisations (Brudney, 1990; Duncombe, 1985). This type of volunteering can be linked to corporate social investment (CSI) which refers to companies' involvement in community activities in order to contribute to the wellbeing of the society they operate in (Katsoulakos \& Katsoulakos, 2006). This means companies' CSI initiatives in the areas of education and training, capacity building, community development and health care (Barthorpe, 2010) are in line with the theories of volunteering. In his 
analysis of extensive research on the scope of volunteer activity and public service, Brown (1999) discovered that volunteer work is often classified by the area of endeavour such as the art, education, environment, health, human service, youth development, private and community foundation, public and societal benefit, adult recreation, religious organisations, and international or foreign concerns. This may be called formal volunteering and it involves companies' CSI activities. Although CSI it involves volunteering from companies' side, it may be beneficial it is combined with volunteering from the beneficiaries (community benefiting from CSI initiatives). This can only be achieved if CSI beneficiaries are willing to volunteer on the CSI initiatives. Thus, the aim of this study is to investigate the community willingness to volunteer on a selected CSI project and identify the benefits or costs associated with volunteering on such project.

\section{The economic theories of volunteering}

The objective of economic related studies of volunteering is to make a link between the individual behaviour to decide to volunteer, and the economic theory to analyse that phenomenon and to explain the choice to volunteer in economic terms (Sardinha, 2003). Economists tend to attribute the production of economic services either to the private, profit-oriented sector, or to the public sector, ignoring mostly the potential of volunteerism. This ignorance leads to the fact that research on volunteering is mainly and abundantly found in political science, sociology and social politics, "while the relevant theories from economics perspective cannot be explicitly identified or have not been sufficiently explored" (Roy \& Ziemek, 2000:1). However, this paper will be based on microeconomic perspective of volunteerism. The central elements of economic theory are scarcity and choice (Mohr et al., 2008). In Economics, every resource is limited/scarce and one of these resources is time. It is impossible to do everything that one needs to do within 24 hours; this paper asks what reason(s) makes volunteers sacrifice their time volunteering? Menchik and Weisbrod (1987), Andreoni (1990), and Freeman (1997) have generally put forward microeconomic models as explanations of volunteer labour supply. These models explaining the determinants of volunteering time include public goods model, private consumption model, impure altruism model and investment model. It is therefore crucial to present each of these models for the purposes of empirical verification of this paper.

Public good model: In the public good model, the assumption is that individuals, who spend some of their time providing a public good or service, do it to increase the total supply of the public good or service. Considering that, this public good or service is defined as non-rivalries and non-excludable. Nonrivalries good means that its consumption by one beneficiary does not reduce its consumption by others. A non-excludable good means that once it has been produced, there is no way of stopping anyone from consuming it (Mohr et al., 2008). Therefore, these individuals obtain an increase in their happiness from increasing the utility of others who benefit from the consumption of the public good or service (Ziemek, 2006). According to Becker (1976) this kind of behaviour of an individual, who is willing to reduce his/her own consumption in order to increase consumption of others, is known as pure altruism. An altruistic person prefers to be defined not only by his/her consumption level, but also by the other people's consumption levels (Badelt, 1999). Therefore, the preferences of altruistic volunteers depend on the private consumption and the aggregate supply of the public good or service (Andreoni, 1990). Thus, the altruistic volunteer will reduce his/her donations when contributions of others increase, and vice versa, in order to maintain the utility obtained from the public goods (Sardinha, 2003:5).

The public good model dismisses the self-interested rationality, which is the fundamental paradigm of economic theory, driven solely by self-interest; individuals interact to benefit each other (Smith, 2005). Many studies have been conducted based on this notion. However, some studies, such those of the Sen (1977), argue convincingly that the self-interest assumption is not supported by empirical results; meaning that this assumption often misleads findings. However, it should be kept in mind that economic theory rests on a set of assumptions about human nature and behaviour. Therefore, in response to this argument some economists such as Becker (1976), and Haltiwanger and Waldman (1993) provide models that explicitly incorporate a population that consists of both altruists and egoists. To understand why some individuals volunteer when others do not, a closer examination of altruism and its role in volunteering appears warranted. 
Altruism and volunteering: The modelling framework significantly affects the empirical interpretation when theorising on what motivates volunteers to make charitable contributions of time or money. It could be questioned on why for example, irrespective of their income level, many households give nothing to charity. This leads to a discussion about the role played by altruism in the individual decision to volunteer. Chou (1996:297) defines altruism as, "Voluntary, intentional behaviour motivated to benefit another that is not motivated by the expectation of eternal rewards or avoiding externally produced punishment or aversive stimuli." According to Monroe (2002:107), altruism is described by these characteristics:

- Altruism must involve action. Good intentions or well-meaning thoughts are not enough.

- The action must have a goal, although the goal may be either conscious or reflexive.

- The goal must be designed to help another. If another person's welfare is an unintended or secondary consequence of behaviour motivated primarily to further one's own welfare, the act is not altruistic.

- Consequences are less important than intentions.

- Altruism sets no conditions. The purpose of the altruistic act is helping another; there is no anticipation or explanation of reward for the altruist. In addition to these five points, conceptualisations of altruism often contain a sixth:

- Altruism must carry the risk of diminution of the actor's well being

For Burns et al. (2006) the relationship between altruism and motivations to volunteer is complex and unclear. According to Pearce (1993), altruistic reasons are given as answer to the question of why people become involved in volunteering. However, others give self-oriented reasons, as is reported by Chambre (1987). Therefore, this means that altruists have lower personal income (or wealth) than those who are not altruists, because altruists do not take advantage of all opportunities to raise their own income (Becker, 1976). This is a reason why this paper asks whether community member are willing to volunteer on projects that benefits them.

Private consumption model: This model is different to the public good model because a person who volunteers derives directly his/her utility from the attitude of giving. The consumption model treats volunteer work as an ordinary consumer good. The individual's utility gained for volunteering an hour's time is presumably equal to the opportunity cost; the value of an hour of leisure time plus any monetary cost associated with an alternative activity of equal utility. Under the consumption model, exogenously determined variables are the individual's income, endowment of available time, non-labour income, and probably a proportional tax, which could be paid. In addition, "volunteers get to enjoy the joy of altruism, and they get to enjoy the consumption of social prestige associated with their position" (Roy \& Ziemek, 2000:15). Furthermore, as stated above, regarding warm-glow, Andreoni (1989:1448) opines that "people have a taste for giving; perhaps they receive status or acclaim, or they simply experience a 'warmglow' from having done their bit." Therefore, it is the process of the volunteering and the rewards associated with carrying out volunteer activity that motivates the individual to give. In the case of CSI, carrying volunteering activities for the company involved and the beneficiaries can bring some rewards

Investment model: This model is also called the impure altruistic model. This model refers to an individual who volunteers with the expectation to gain something in return such as a better opportunity in the future. For example, if a student gets involved in volunteering activities expecting a scholarship or professional qualification in return. For this reason, the model is called the investment model (Sardinha, 2003). Under this model, volunteerism should be regarded as investment behaviour. This investment could be achieved through human capital accumulation by volunteering to receive training and gain new skills. This will increase chances of getting and performing jobs of higher pay than those jobs, which the volunteer would be able to acquire without his or her volunteer experience (Ziemek, 2006). This model expresses the importance of reciprocity. In this case, volunteering has an ulterior motive giving in order to receive something back in return, which may not be measured in terms of material. In addition, a person may engage in volunteering due to influence from others' experience through volunteerism. Therefore, Ziemek's (2006) investment model has two possible effects derived from private contribution from others namely, signalling effect and job-opportunity effect. In singling effect a person will be enticed to do more of volunteering if many of his/her colleagues at work place also volunteer. In this case, a positive relationship between a person's contributions and the contributions by other volunteers is 
established (one's contribution being a dependant variable). Job-opportunity effect is about the relationship, which can be established between public spending levels and volunteer contributions. Assume that CSI projects increases spending in the health sector, this will lead to an expansion of job opportunities and labour demand in the sector. Additionally, individuals may volunteer in CSI projects with expectation of gaining some skills and experiences that may create future job opportunity. This is the case with the current study because the CSI project of re-roofing houses was expected to provide some skills and experience to community members involved.

\section{Methodology}

Sampling, data collection and questionnaire design: Data were collected during November and December 2013 from 250 beneficiary of a CSI project of re-roofing houses of community members in a low income area of South Africa. This CSI project was implemented by a company referred to as company $\mathrm{X}$ in this study, for the sake of anonymity. Data collection process involved fieldworkers who interviewed household's members by reading the questions aloud and writing down the answers given by interviewees. The design of the questionnaire, used for obtaining the necessary information, had two major parts which cover two different aspects. The first part captured information on households' sociodemographic characteristics; while the second part contains questions about participants' willingness on volunteering on the CSI project. The questionnaire was pretested within a small sample of 30 participants who were not part of the survey. After the preliminary test, the researchers were able to make an observation on the participants' reactions and the problems inherent in the survey were identified and corrected. The final stage of the study used a sample of 250 questionnaires but only 247 of them were deemed legible for analysis. Test for internal consistency showed that Cronbach's $\alpha(0.8)$ the second part of the questionnaire was above the benchmark of 0.7, confirming the reliability of the scale used to measure willingness to volunteer on the CSI project. The data collected from the survey questionnaire was supplemented by more information gathered through interviews with community members, and company representatives. Six participants 3 community members, 1 community leader and 2 company's representatives were interviewed. These interviewees were selected based on their involvement in the CSI project; implying that this selection followed a purposive sampling method, which allows the researcher the flexibility and opportunity to select participants based on the quality of information they possess (Black, 2013).

Evaluation Methods: This study adopted an evaluation method that combines qualitative evidence with a quantitative survey process. Qualitative methods involved the process of identifying major themes from interviews with community leaders, company representatives and open questions to the beneficiaries. On the other hand, a quantitative method used analysis (such as descriptive statistics and graphical analysis) to identify patterns of the community's wiliness to volunteer on the CSI project.

\section{Results and Discussion}

Participants' demographic information: This sub-section provides detailed demographic information of participants. The total number of people within the 247 surveyed households was 931 . The average household size was approximately 3.8 persons, with a maximum of 10 members and a minimum of 1 member per a household. Out of 247 households, females accounted for $63.4 \%$ of the household heads; while males accounted for $36.4 \%$. Age group showed that about 46 percent of the household's heads had reached retirement age. It was noted that 51 percent of the household's heads were not in labour force; meaning that most of them were old people, not willing to work, or disabled. Furthermore, 76 percent of economically active household's heads (those in labour force) were unemployed and majority of the sampled household's heads (77\%) did not have the primary education.

Community willingness and ability to work on CSI: Beneficiaries' willingness to work on the CSI project was captured by 3 questions, which asked whether beneficiaries were willing to volunteer, work on the CSI project for a wage and whether some of them had required skills before implementation of the CSI project. The distribution of the responses to these questions, in Figure 1 shows that only 30 percent of participants were willing to do some volunteering work on the CSI project that benefited them. Surprisingly, 72.1 percent of participants would have worked on CSI project of re-roofing their houses provided that they were paid. However, it is interesting to see that the majority of those who disagree 
with volunteering on re-roofing their houses did not even have the required skills. Similarly, many of those who were willing to be employed with pay strongly agreed that they did not have the required skills. This shows a miss-match between the skills and the willingness to work on this CSI project. One can say this was an opportunity missed by unemployed beneficiaries as volunteering could had given them some skills that could assist them in finding a job at the end of this SRI project. This finding is contrary to investment model of volunteering which states that individuals volunteer because of expectation to gain something in return such as a better opportunity in the future (Ziemek, 2006). Thus, beneficiaries of this CSI project denied investment opportunity associated with volunteerism. This denied skills and experience that could provide opportunity for future employment to unemployed community members.

Qualitative analysis confirms that community members were not willing to do any volunteering work on the CSI project of re-roofing their houses. However, it was mentioned in the interview with the company's representative and community leaders that:

We had volunteers but none of them was from community members who benefited from the CSI project. This team of volunteers was made of employees of the company $X$, who received the necessary training needed to work on the project. These employees volunteered to assist the community but community members who were beneficiary of the project were not willing to volunteer the CSI project.

Figure 1: Beneficiaries willingness and ability to work on the project

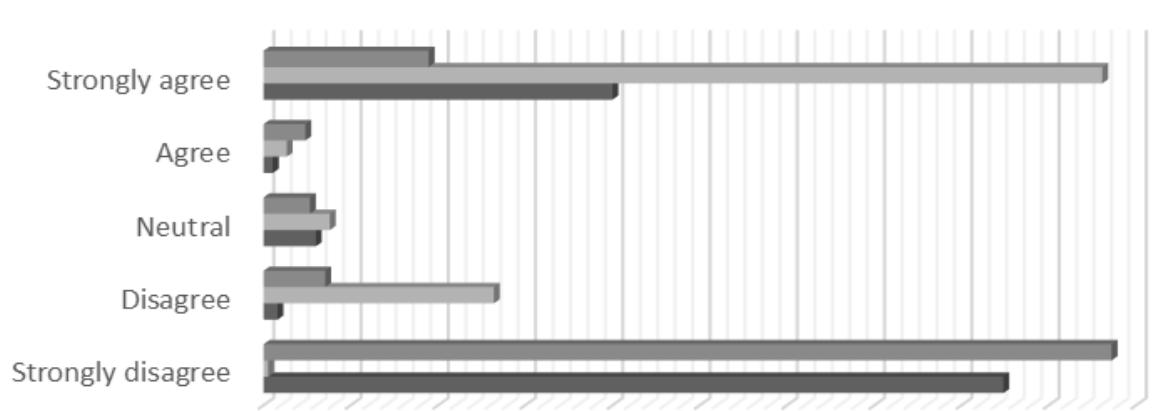

$0.0 \% \quad 7.5 \% \quad 15.0 \% 22.5 \% 30.0 \% 37.5 \% \quad 45.0 \% 52.5 \% \quad 60.0 \% 67.5 \% \quad 75.0 \%$

\begin{tabular}{|l|c|c|c|c|c|}
\cline { 2 - 6 } \multicolumn{1}{c|}{} & $\begin{array}{c}\text { Strongly } \\
\text { disagree }\end{array}$ & Disagree & Neutral & Agree & Strongly agree \\
\hline - Had required Skill & $72.9 \%$ & $5.3 \%$ & $4.0 \%$ & $3.6 \%$ & $14.2 \%$ \\
\hline - willing to work with pay & $0.4 \%$ & $19.8 \%$ & $5.7 \%$ & $2.0 \%$ & $72.1 \%$ \\
\hline - willing to volonteer & $63.6 \%$ & $1.2 \%$ & $4.5 \%$ & $0.8 \%$ & $30.0 \%$ \\
\hline
\end{tabular}

These responses for interviews suggest that by volunteering, members of community could have benefited from this training, which offered some basic skills that could have used in the future to find a job. The element of training is very important in the literature of CSI which emphasises on the role of CSI initiatives in developing local communities through capacity building (Luning, 2012; Rajak, 2008).Thus, volunteering can encourage community members to participate in SCI projects which could exposed them to training that can increase the chance of obtaining employment in the future. In the context of this study, this can only hold if the CSI initiative of re-roofing houses provided enough skills/experience that can assist community members to get employment after the project.

Missed opportunities due non- volunteering on the CSI project: In long-term, community member could be the future employment (after the project) due to the skills gained from volunteering on the SCI project. Responses to questions which assess whether training gained for the CSI of re-roofing houses provided future employment opportunity are summarised in Table1. Participants' responses, in this table, show that 85 percent $(83+2)$ of participants at least agreed that the CSI project provided useful skills to the community; while 10.5 percent disagreed with this statement. Additionally, 87.4 percent $(84.6+2.8)$ at least agreed that community members were able to use the skills gained from the project to get a job somewhere else. This is an indication that volunteering on this CSI project could have been an investment to community members who were mostly unemployed. Qualitative evaluation also confirmed this. It was stated in the interviews that members of the local community, who worked on the project 
were trained beforehand and received certificates of participation at the end of project. Some of community members mentioned that:

Most of our neighbour who worked on the project used the skills gained from the project to find a job elsewhere after the completion of the CSI project.

Results indicated that training and skills gained from the CSI was a good investment to the community members that could have exploited if community members had a good attitude towards volunteering. These findings are similar to those of other studies (Abeysuriya et al., 2007; Derwall et al., 2011; Hossain et al., 2013; Kang et al., 2010) which found that SRI initiatives contributed positively to development of the local community. This is also in line with the CSI strategy of community investing which seeks to improve the living standards of the community members (Viviers et al., 2009). Linking this with the investment model of volunteering, this CSI strategy of community investing can be fully achieved if community members, (especially the beneficiary of CSI projects) are willing to be involved in CSI initiatives through volunteering.

\section{Conclusion and Recommendations}

Findings of this study highlight the investment benefits associated with volunteering and identified the major challenge associated with community members' attitude towards volunteering. Based on the investment of volunteerism, this paper showed that beneficiaries of CSI denied investment opportunities associated with volunteerism. This paper's qualitative analysis revealed that the implementation of the CSI project involved skills which opened employment opportunities to community members who worked on the CSI project. This implies that volunteering on the CSI project could provide community members with some skills and experience that can assist in minimising the challenge of unemployment faced communities of low income areas. However, quantitative results showed that a large number of unskilled and unemployed community members were not willing to volunteer on the CSI project. Based on the investment model of volunteering, these community members, who were beneficiaries of the CSI project, denied an investment opportunity associated with volunteering. This means that community members' attitude towards volunteering on CSI projects has to change in order to increase the CSIs' effect on the community. Therefore, companies and community leaders should work together to motivate beneficiaries of the CSI projects to meet companies half-way through volunteering. This will allow community members to realise the investment opportunities associated with volunteering on the CSI projects. These findings are important in improving the effectiveness of the CSI projects in low income areas. Future research could therefore explore whether community members' attitude towards volunteering changes when communities of a high income areas are considered. Future research can further explore whether the investment model of volunteerism can be used to explain South African companies' involvement in CSI initiatives.

\section{Reference}

Abeysuriya, K., Mitchell, C. \& White, S. (2007). Can corporate social responsibility resolve the sanitation question in developing Asian countries? Ecological Economics, 62, 174-183.

Andreoni, J. (1989). Giving with impure Altruism: Application to Charity and Ricardian Equivalence. Journal of Political Economy, 97(6), 1447-1458.

Andreoni, J. (1990). Impure Altruism and Donations to Public Goods: A Theory of Warm-Glow Giving. The Economic Journal, 100(6), 464-477.

Ascoli, U. \& Cnaan, R. A. 1997. Volunteering for Human Service Provisions: Lessons from Italy and the USA. Social Indicators Research, 40, 299-327.

Badelt, C. (1999). Handbuch der Nonprofit Organisation: Struktur und Management $\left(2^{\text {nd }}\right.$ Ed), Stuttgart: Schaffer-Poeschel.

Barthorpe, S. (2010). Implementing corporate social responsibility in the UK construction industry. Property Management, 28, 4-17.

Becker, G. S. (1976). Altruism, Egoism, and Genetic Fitness: Economics and Sociobiology. Journal of Economic Literature, 14(3), 817-826.

Black, K. (2013). Applied Business Statistics: Making Better Business Decisions (2 ${ }^{\text {nd }}$ Ed). Singapore: John Wiley \& Sons, Inc. 
Brown, E. (1999). The scope of Volunteer Activity and Public Service. Law and Contemporary Problems, 62(4), 17-42.

Brudney, J. L. (1990). Fostering volunteer programs in the public sector, San Francisco: Jossey-Bass.

Burns, D. J., Reid, J. S., Toncar, M., Faweett, J. \& Anderson, C. (2006). Motivations to Volunteer: The Role of Altruism. International Review on Public and Non Profit Marketing, 3(2), 79-91.

Chambre, S. M. (1987). Good Deeds in Old Age: Volunteering by the New Leisure Class, Lexington: Lexington Books.

Chou, K. L. (1996). The rushton, chrisjohn and fekken self-report altruism scale. Personality and Individual Differences, 21,297-298.

Derwall, J., Koedijk, K. \& Horst, J. (2011). A tale of values-driven and pfoti-seeking social investors. Journal of Banking and Finance, 35, 2137-2147.

Duncombe, S. (1985). Volunteers in city government: Advantages, disadvantages, and uses. National Civic Review, 79, 356-364.

Ellis, S. J. \& Noyes, K. H. (1990). By the people, San Francisco: Jossey-Bass.

Freeman, R. B. (1997). Working for Nothing: the Supply of Volunteer Labor. Journal of Labor Economics, 15(1), S140-S166.

Haltiwanger, J. \& Waldman, M. (1993). Role of Altruism in Economic Interaction. JEBAO, 21, 1-15.

Hossain, T., Siwar, C. J. \& Bhuiyan, A. (2013). Corporate Social Responsibility (CSR) for Global Market Access: A Malaysian. Research Journal of Applied Sciences, Engineering and Technology, 5(1), 60-65.

Kang, K., Lee, S. \& Huh, C. (2010). Impacts of positive and negative corporate social responsibility activities on company performance in the hospitality industry. International Journal of Hospitality Management, 29, 72-82.

Katsoulakos, P. \& Katsoulakos, Y. (2006). A multidimensional view of corporate social responsibility: th4CR approach to corporate responsibility. 4CR Working Papers A. 1.5. Retrieved 22 July 2013, from http://www.csrquest.net/uploadfiles/4CR\%20A1.5.pdf.

Luning, S. (2012). Corporate Social Responsibility (CSR) for exploration: Consultants, companies and communities in processes of engagements. Policy Resources, 37, 205-211.

Menchik, P. L. \& Weisbrod, B. A. (1987). Volunteer labour supply. Journal of Public Economics, 32, 159-183.

Mizenko, W. M. \& Smith, L. A. (1991). The Significance of Volunteering, Philadelphia: Energize.

Mohr, P., Fourie, L. \& Associates (2008). Economics for South African Students (4th ed), Pretoria: Van Schaik.

Monroe, K. R. (2002). Explicating altruism. In Post, S.G, Underwood, L.G, Schloss, J.P \&Hurlbut, W.B. (Eds). Altruism and Altruistic Love: Science, Philosophy, and Religion in Dialogue: 106-122. New York: Oxford University Press.

Pearce, J. (1993). Volunteers: the Organizational behaviour of Unpaid Workers. New York, Routledge.

Penner, L. A. (2004). Volunteerism and Social Problems: Making things better or worse. Journal of Social Issues, 60, 645-666.

Rajak, D. (2008). 'Uplift and empower': The market, morality and corporate responsibility on South Africa's platinum belt. Research in Economic Anthropology, 28, 297-324.

Roy, K. \& Ziemek, S. (2000). On the Economics of Volunteering. ZEF Discussion Papers on Development Policy no 31.

Sardinha, B. M. B. (2003). To Volunteer-Application of the Utility Function. Paper presented at $15^{\text {th }}$ Annual Meeting on Socio-Economics, Knowledge, Education and Future Societies. Retrieved on 17 July 2014 from http://www.docstoc.com/docs/40958500/To-be-a-volunteer---applicationof-the-utility-function.

Sen, A. K. (1977). Rational Fools: A Critique of the Behavioral Foundations of Economic Theory. Philosophy and Public Affairs, 6(4), 317-344.

Smith, A. (2005). An Enquiry into the Nature and Causes of Wealth of Nation: An Electronic Classics Series Publication, Pennsylvania: The Pennsylvania State University.

Viviers, S., Bosch, J., Smit, E. \& Buijs, A. (2009). Responsible investing in South Africa. Investment Analysts Journal, 69, 1-16.

Wilson, J. \& Musick, M. (1997). Who cares? Towards an integrated theory of volunteer work. American Sociological Review, 62(5), 694-713.

Wilson, J. (2000). Volunteering. Annual Review of Sociology, 26, 215-240.

Ziemek, S. (2006). Economic Analysis of Volunteers' Motivations- A Cross-Country Study. Journal of SocioEconomics, 35(3), 532-555. 